\title{
Determination of Correlation for Extreme Metocean Variables
}

\author{
Zafarullah Nizamani ${ }^{1,{ }^{*}}$,Lim Woan Yih ${ }^{1}$, M.M.A Wahab $^{2}$, and Zahiraniza Mustaffa ${ }^{2}$ \\ ${ }^{1}$ Department of Environmental Engineering, Universiti Tunku Abdul Rahman (UTAR), P.C. 31900, \\ Kampar, Perak Darul Ridzuan, Malaysia \\ ${ }^{2}$ Department of Civil Engineering, Universiti Teknologi PETRONAS, Malaysia, 32610 Bandar Seri \\ Iskandar, Perak Darul Ridzuan, Malaysia
}

\begin{abstract}
Metocean environmental load includes wind, wave and currents. Offshore structures are designed for two environmental load design conditions i.e. extreme and operational load conditions of environmental loads are evaluated. The ccorrelation between load variables using Joint probability distribution, Pearson correlation coefficient and Spearman's rank correlation coefficients methods in Peninsular Malaysia (PM), Sabah and Sarawak are computed. Joint probability distribution method is considered as a reliable method among three different methods to determine the relationship between load variables. The PM has good correlation between the wind-wave and wave-current; Sabah has both strong relationships of wind-wave and wind-current with 50 year return period; Sarawak has good correlation between wind and current in both 50 years and 100 years return period. Since Sabah has good correlation between the associated load variables, no matter in 50 years or 100 years of return period of load combination. Thus, method 1 of ISO 19901-1, specimen provides guideline for metocean loading conditions, can be adopted for design for offshore structure in Sabah. However, due to weak correlations in PM and Sarawak, this method cannot be applied and method 2, which is current practice in offshore industry, should continueto be used.
\end{abstract}

\section{Introduction}

Offshore Malaysia is surrounded by various seas such as the South China Sea, Straits of Malacca and Sulu Sea. Offshore structures are designed using different load combinations based on operating and extreme conditions and whichever provides maximum stresses that load combination is considered to be governing the design. Extreme events like typhoon, storm and tsunami may occur once during the design life of offshore jacket platform. In South East Asia, typhoon is the extreme event, with a return period of 100 years and can damage the structures. Thus, to confirm the structural reliability of the jacket platformsduring its design life, operational 1-10 year and extreme loads 50-100 year data are used. Typhoons Vamei as well as tropical storm Greg is considered as the extreme

*Corresponding author: zafarullah@utar.edu.my 
events which has occurred in past in Malaysia and they still may recur at any time once again. ISO 19901 recommends three different methods to analyse and determine the stresses in the jacket[1]. Correlation is evaluated between wind, wave and current using three methods of analysis, i.e. Joint probability distribution, Pearson correlation coefficient and Spearman's rank correlation coefficient methods. When all three variables occur concurrently, in the same direction and with same return period, they will cause maximum stresses. This will cause a huge impact on the jackets. On the contrary, if there is no correlation between variables, then we need to analyse the data to determine the relation between the variables with different return period.

\section{Literature Review}

The wind, wave and current are considered to be random variables and may differ with time[1-9]. The jacket platforms are designed for extreme load conditions this is to make sure its structural reliability throughout its design life [10]. During the actual life of the jacket, extreme events may or may not occur during its operating conditions, but still there is low probability of its occurrence exists, with the impacts on the structure [11]. ISO 19901-1 suggests that if possible before actual design of offshore structure is undertaken, the joint probability of occurrence of uncertain metocean variables must be evaluated [1]. The design practice followed in Malaysia is based on return period of 100 year loads without giving any consideration for joint probability and the structure designed with this procedure will be safe but not economical. The joint probability analysis includes the determination of relationship between random variables which not only show their relationship, but also their distribution [12]. The knowledge about the joint probability distribution is an added benefit to the design engineer in considering the metocean loads on jacket structure. ISO 19901-1, recommends, that jackets to be analysed against long term return period metocean data typically 100 years return period metocean data should be considered. The ISO 19901-1 requires one of the three methods, should be adopted for the evaluation of environmental load parameters. 1) 100 year return period of wave height with associated period, wind or/and current speeds should be used. 2) The second method is being applied by design companies in Malaysia i.e. 100 year wave height, wave period, wind and current speed should be considered. 3) Any combination of wave height, period, wind and current speed that results in a) the global extreme environmental load acting on the offshore jacket, b) relevant global response of the jacket resulting from base shear or overturning moment.

For joint probability distribution method marginal and conditional distributions are evaluated. There are three techniques for the determination of the correlation. joint probability distribution method, Pearson correlation coefficient technique and Spearman's rank correlation coefficient. The Pearson correlation coefficient uses the given data for analysis. Spearman's rank correlation coefficient technique, before determining the correlation, ranks the given,data first.Correlation defines the relationship between the wind, wave and current, whereas the correlation coefficient shows the strength of a correlation. It needs to be evaluated here, whether the variables are related to each other or not, along with the strength of the relationship. The variables are considered to be related, if a variable (X) indicates the influence on the second variable (Y)[13].

Correlation coefficient range lies between -1.0 to 1.0 and is dimensionless [13-14]. Positive correlation indicates that the value of the variable is as high as 1.0. When one variable increases in value and another decreases it is considered to be negatively correlated variable. If the value of correlation coefficient is \pm 1.0 it is considered to be good correlation. A correlation coefficient of zero indicates that there is no linear relationship 
between the independent variables [15]. In case of difference among the values, it is recommended to take the lesser value.

The correlation tests are conducted to find the correlation between the metocean parameters for the dependent and independent variables. This is to describe the characteristics of the variables by classifying the exact association among variables [16]. The first stage is to determine the relationship between variables, whether they can be considered as dependent or independent. Subsequently, before the correlation test is carried out, the measurement scale for each variable needs to be determined as well as the number of variables involved. The final stage is to do the variable analysis using their relationship. Joint probability distribution is a study of considering the relationship between the variables together rather than taking their values separately. Joint distribution demonstrates that in what way two variables are associated and distributed [12]. Probability distributions are used for the determination of structural reliability. The probability distribution is determined for each variable, with information on mean, variance and standard deviation [12]. Joint probability distribution is advantageous for structural reliability analysis (SRA) because it helps to forecast of limit state function for structural damage [3]. The physics of offshore metocean parameters indicate that these variables should undergo multivariate analysis as compared with the values indicated by a single variable [10]. The advantage of using joint distribution is to determine the complex measured data [17]. The main difference between the Pearson and Spearman methods is Spearman uses ranked data instead of original data to conduct the research [14-15].

\section{Methodology}

In this study, metocean data, provided by government agency i.e. PETRONAS from three regions of Malaysia i.e. Peninsular Malaysia, Sabah and Sarawak is used to be analysed. The available data is a processed data and it is in shape of $1,10,50$ and 100 years. A research was conducted where three statistical variables were considered independent; in this study a joint distribution is being considered [18]. In this study,50 and 100 year return perioddata is analysed to determine their co-relation. The available data belongs to 20 from PM, 8 from Sabah and 18 from Sarawak respectively. The hypothesis are built as shown in Figure 1 which shows that when the associated load variables have a positive relationship, all the variables will be acting in the same direction and are parallel. Thus, the loads produced, by use of this method, can provide severe case with regard to the forces on the structure. This will lead to the higher design loads being determined and thus uneconomical structure will result. This is because, to safeguard the safety of the structure, the resistance of the structure should be higher. This is achieved by using the highest grade of steel or enlarging the cross sectional area of the component. However, in case of associated variables have negative relationship, i.e. acting in the opposite direction, less force will be acting on the jacket and this can produce jacket which is not only safe but also economical.

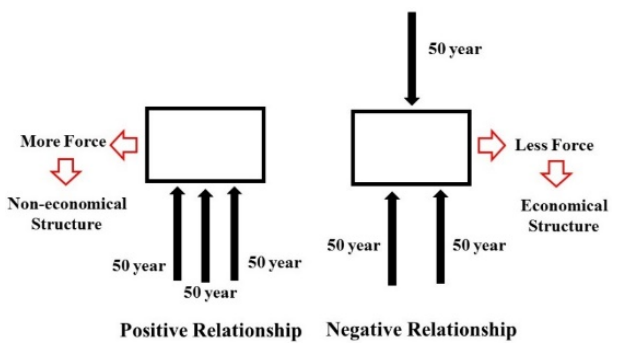

Fig. 1.Effect of different assumed Load variables acting either in same or opposite directions. 


\subsection{Joint Probability Distribution}

Joint probability distribution is used to determine the probability distribution between two uncertain metocean random variables as shown in Equation (1) by $\mathrm{X}$ and Y. Marginal distribution of $\mathrm{X}$ given that $\mathrm{Y}$ is determined.

$$
P(X=x \text { and } Y=y)=\frac{P(X=x \mid Y=y)}{P(Y=y)}
$$

Here, $\mathrm{X}$ and $\mathrm{Y}$ are two different load variables. Equations (2-4) are used to determine mean $(\mu)$, variance $\left(\sigma^{2}\right)$ and standard deviation $(\sigma)$ respectively.

$$
\begin{gathered}
\mu=E(X)=\sum_{i=1}^{k} v_{i} p\left(v_{i}\right) \\
\sigma^{2}=\operatorname{Var}(X)=\sum_{i=1}^{k}\left(v_{i}-E(X)\right)^{2} p\left(v_{i}\right) \\
\sigma=\operatorname{Stdev}(X)=\sqrt{\operatorname{Var}(X)}
\end{gathered}
$$

Here, $x_{i}$ is random load variable and $p\left(x_{i}\right)$ is the random variable probability. The relationship between two random variables is determined by using the equations (5-6) by using the covariance and correlation.

$$
\begin{gathered}
\operatorname{Cov}(X, Y)=\sum_{i=1}^{k}\left(x_{i}-E(X)\right)\left(y_{i}-E(Y)\right) p\left(x_{i}, y_{i}\right) \\
\operatorname{Corr}(X, Y)=\frac{\operatorname{Cov}(X, Y)}{\operatorname{Stdev}(X) \times \operatorname{Stdev}(Y)}
\end{gathered}
$$

\subsection{Pearson Correlation Coefficient}

In the Pearson method the, $\mathrm{xy}, \mathrm{x}^{2}$, and $\mathrm{y}^{2}$ are used to estimate the correlation coefficient. Here, $x$ and y represent two different load variables. The correlation coefficient, $r_{p}$ is determined by using Equation (7).

$$
\text { Correlation }\left(r_{p}\right)=\frac{\left[\left(n \times \sum x y\right)-\left(\sum x \times \sum y\right)\right]}{\sqrt{\left[n\left(\left(\sum x^{2}\right)-\left(\sum x\right)^{2}\right] \times\left[n\left(\sum y^{2}\right)-\left(\sum y\right)^{2}\right]\right.}}
$$

Here, $n$ is a total set of data, $x y$ has multiplied the $x$ value with $y$ value, $x^{2}$ is square of $x$ value, $y^{2}$ is the square of $y$ value, $\Sigma x$ is the sum of $x$ values , $\Sigma y$ is the sum of $y$ values, $\Sigma x y$ is the sum of the product of $x y, \Sigma x^{2}$ is the sum of $x^{2}, \Sigma y^{2}$ is the sum of $y^{2}$.

\subsection{Spearman's Rank Correlation Coefficient}

For Spearman's method, the values of $\mathrm{x}$ and $\mathrm{y}$ in separate columns would be ranked by using Excel formula RANK.AVG(x) and RANK.AVG(y) respectively. The correlation coefficient (rs) is determined next and that is calculated by using Excel formula CORREL $(\operatorname{Rank}(\mathrm{x}), \operatorname{Rank}(\mathrm{y}))$. Here, $\mathrm{x}$ and $\mathrm{y}$ are two different load variables. 


\section{Result and Discussion}

Correlation coefficient strength between the uncertain metocean variables in three regions of offshore Malaysia is determined using three different methods of correlation. Table 1 and Fig. 2 are based on the data of 50 year return period. It shows that a positive correlation exists between wind and wave using joint distribution, Pearson and Spearman's methods, i.e. the coefficients found are $0.820,0.849$ and 0.859 respectively. Table 1 and Fig. 3 show that the relationship between mean wind speed and current velocity is good in both joint distributions and Pearson's method, but the relationship in Spearman's method is found to be not strong. Table 1 shows that, in joint distribution, correlation coefficient between wave height and current velocity of surface is less than 0.5 , while for Pearson and Spearman is around 0.2. Fig. 4 shows that the relationship for Joint distribution is average and positive between wave and current; but, for Pearson and Spearman is a weak and positive.

Table 1.Correlation Coefficients for Sabah Region.

\begin{tabular}{|c|c|c|c|c|c|c|}
\hline \multirow{2}{*}{ Methods } & $\begin{array}{c}\text { Wind } \\
\text { and } \\
\text { Wave }\end{array}$ & $\begin{array}{c}\text { Wind and } \\
\text { Current }\end{array}$ & $\begin{array}{c}\text { Wave and } \\
\text { Current }\end{array}$ & $\begin{array}{c}\text { Wind } \\
\text { and } \\
\text { Wave }\end{array}$ & $\begin{array}{c}\text { Wind and } \\
\text { Current }\end{array}$ & $\begin{array}{c}\text { Wave and } \\
\text { Current }\end{array}$ \\
\cline { 2 - 7 } & 50 year & 50 year & 50 year & 100 year & 100 year & 100 year \\
\hline $\begin{array}{c}\text { Joint } \\
\text { Probability } \\
\text { Distribution }\end{array}$ & 0.820 & 0.649 & 0.406 & 0.483 & 0.617 & 0.520 \\
\hline $\begin{array}{c}\text { Pearson } \\
\text { Correlation }\end{array}$ & 0.849 & 0.649 & 0.163 & 0.379 & 0.617 & 0.436 \\
\hline $\begin{array}{c}\text { Spearman's } \\
\text { Rank } \\
\text { Correlation }\end{array}$ & 0.859 & 0.270 & 0.163 & 0.220 & 0.015 & 0.325 \\
\hline
\end{tabular}

Table 2 and Fig. 1 also shows the correlation coefficient for 100-year return period. It is found to be an average and positive between wind and wave for joint distribution. The

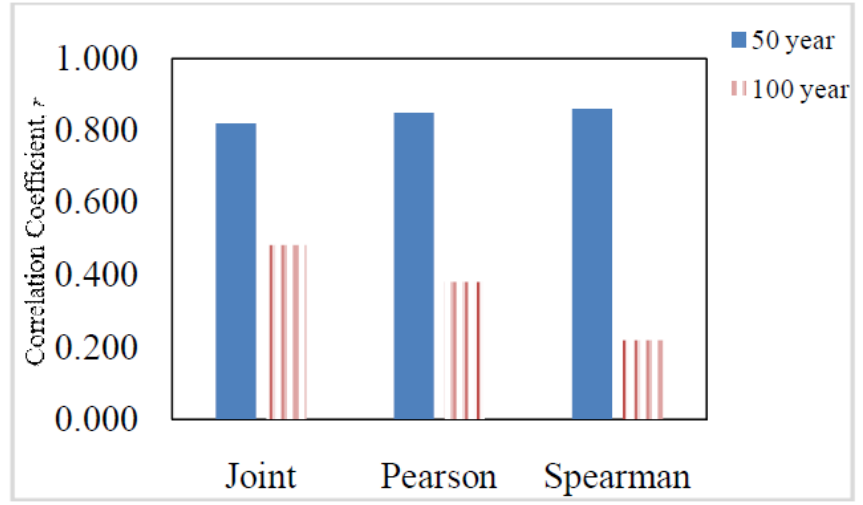

Fig. 2. Correlation Coefficient for Wind and Wave Sabah. 


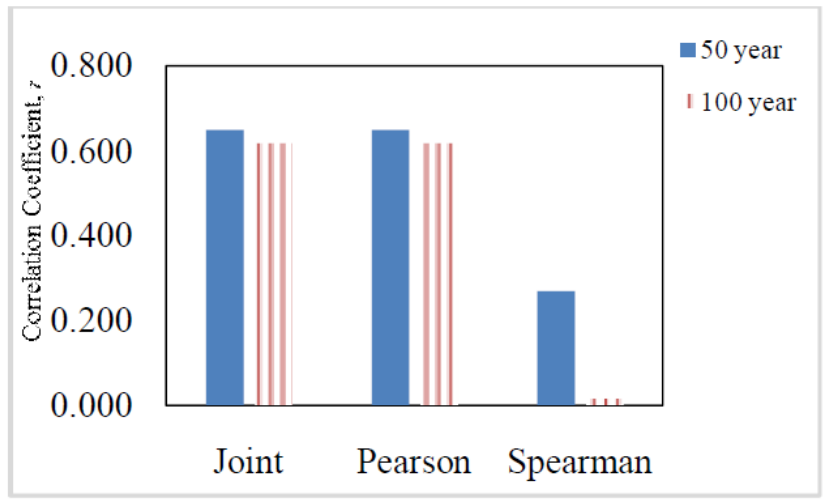

Fig. 3.Correlation Coefficient for Wind and Current_Sabah.

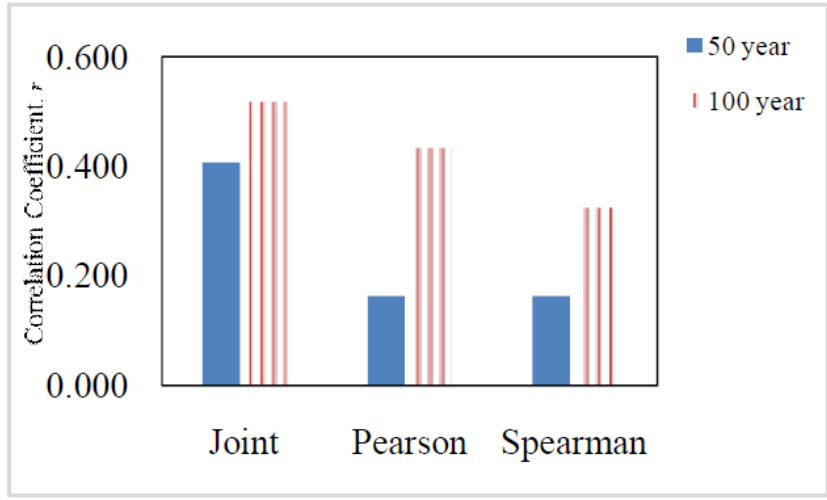

Fig. 4.Correlation Coefficient for Wave and Current_ Sabah.

Coefficient between the wind speed and wave height for Pearson and Spearman shows a weak relationship. Table 2 and Fig. 3 shows that the correlation coefficient is 0.617 between wind speed and current in Joint distribution. The Pearson and Spearman methods showed a correlation for wind and current as 0.617 and 0.015 respectively. Thus, it can be concluded that the relationship for wind and current using Joint distribution and Pearson is strong and positive. The same trend is found between wave and current as shown in Fig. 4. The Table 1 and Fig. 4 show that the correlation coefficient between wave and current. The relationship for both Joint distribution and Pearson is average and positively related and weak for Spearman between wave and current. In conclusion, for return periods of 50 years, we can recommend that, Sabah has strong and positive relationships between wind-wave and wind-current. For return periods of 100 years, it has a strong and positive relationship between wind and current. This could be due to the influence of the tropical Storm Greg and data collected was during that period. The maximum difference between Joint distribution and Pearson is in a range of $0.0-0.244$ respectively, whereas for Joint and Spearman it is in range of $0.015-0.602$ respectively. The results show that the difference between the joint distribution and the Pearson is smaller as compared tojoint distribution and Spearman. The reason for the difference between joint and Spearman is due to Spearman uses rank data [16], which is not the case when we use joint and Pearson method. However, as design of offshore structures follow[1]metocean specifications, which recommends joint probability distributions method to be used for metocean variables for the correlation. Thus, the joint probability distribution takes the precedence when there is an inconsistency among other methods. 
Table 2 shows that Sabah has a strong correlation of all variables for return periods of 50 and 100 years. Thus, it can be concluded that jacket platforms for Sabah can be designed using the associated variables for return periods of 50 and 100. Furthermore, Method 1 of ISO 19901-1 can be applied to the design of jackets in Sabah. Whereas, it cannot be used in the PM and Sarawak in terms of associated variables for return periods of 50 and 100 years because of their weak correlations as shown in Table 2. Therefore, Method 2 of ISO 199011 which is the present practice in Malaysia should continue to be applied for PM and Sarawak until new data is made available. Table 2 shows negative co-relationship between two load variables, in some regions regardless of good or weak correlation, i.e. PM and Sabah obtained good, but the negative relationship correlation between wind and current for 50 year return period.

Table 2.Correlations for 50 and 100 Year Return Periods

\begin{tabular}{|c|c|c|c|c|c|}
\hline Return & Correlation & \multicolumn{2}{|c|}{ Good } & \multicolumn{2}{c|}{ Weak } \\
\cline { 3 - 6 } Period & between variables & Positive & Negative & Positive & Negative \\
\hline 50 year & Wind and Wave & PM, Sabah & - & Sarawak & - \\
\cline { 2 - 6 } & Wind and Current & Sabah, Sarawak & - & - & PM \\
\cline { 2 - 6 } & Wave and Current & - & PM, & Sarawak & - \\
& & & Sabah & & \\
\hline 100 year & Wind and Wave & - & Sabah & PM, Sarawak & - \\
\cline { 2 - 6 } & Wind and Current & Sabah, Sarawak & - & PM & - \\
\cline { 2 - 6 } & Wave and Current & Sabah & - & Sarawak & PM \\
\hline
\end{tabular}

\section{Conclusion}

The correlation between wind-wave and wave-current is strong in Peninsular Malaysia. Similarly correlation between wind-wave and wind-current is strong in Sabah for return periods of 50 years. Sabah has shown a strong relationship between wind and current for return periods 50 and 100 years. For return periods of 50 and 100 years, the metocean data for wind and current Sarawak provided good correlation. The highest difference in correlation coefficients in Joint probability distribution and Pearson is 0.244. The difference of minimum and maximum correlation coefficient for Joint probability distribution and Spearman are 0.015 and 0.602 respectively. It can be concluded that for associated variables Sabah has shown the best correlation for both return periods and ISO method 1 should be used for design of jacket platforms. Whereas PM and Sarawak regions are considered to have a weak overall correlation and therefore, ISO method 2, should to be continued for PM and Sarawak.

The first author would like to acknowledge the research grant IPSR/RMC/UTARRF/2014-C2/Z01 provided by the UniversitiTunku Abdul Rahman, Malaysia.

\section{References}

[1] ISO 19901-1 Petroleum and Natural Gas Industries - Specific Requirements for Offshore Structures - Part 1: Metocean Design and Operating Considerations, (2005)

[2] E.M.Bitner-Gregersen, K.C. Ewans and M.C. Johnson, Some Uncertainties Associated with Wind and Wave Description and Their Importance for Engineering Applications. Ocean Engineering, 86, 11-25, (2014)

[3] E. M.Bitner-Gregersen, Joint Met-Ocean Description for Design and Operations of Marine Structures. Applied Ocean Research, 51, 279-292, (2015 
[4] K. Burry,Statistical Distribution in Engineering. New York: The Press Syndicate of the University of Cambridge, (1999)

[5] S. K.Chakrabarti, Hydrodynamics of offshore structures. United Kingdom: WIT Press, (1986)

[6] C.P. Chang, C.H. Liu and C.H.Kuo, Typhoon Vamei: An Equatorial Tropical Cyclone Formation. Geophysical Research Letters, 30(3), 50, (2003)

[7] K.Ewansand and P.Jonathan, Evaluating Environmental Joint Extremes for the Offshore Industry using the Conditional Extremes Model. Journal of Marine System, 130, 124-130, (2014)

[8] H.Mallahzadeh, G.Najafian, M.K.A Husain and N.I.M.Zaki, Derivation of Probability Distribution of Extreme Offshore Structural Response due to Combined Wave and Current Loading from the Probability Distribution of Extreme Surface Elevations. 7th International ASRANet Conference, (2014)

[9] Q. Yiquan, Z. Zhixu and S.Ping, , Extreme Wind, Wave and Current in Deep Water of South China Sea. International Journal of Offshore and Polar Engineering, 20(1), 1823, (2010)

[10]P. Jonathan, K. Ewans and G. Forristall, Statistical Estimation of Extreme Ocean Environments: The Requirement for Modelling Directionality and Other Covariate Effects. Ocean Engineering, 35(11-12), 1211-1225, (2008)

[11]P. Jonathanand K. Ewans, Statistical Modelling of Extreme Ocean Environments for Marine Design: A Review. Ocean Engineering, 62, 91-109, (2013)

[12] S.C. Albright, W.L. Winston and C.J. Zappe, Data Analysis \& Decision Making with Microsoft Excel, 3rd ed. Mason, USA: Thomson South-Western, (2012)

[13]N.S, Chok, Pearson's versus Spearman's and Kendall's Correlation Coefficients for Continuous Data. Master's Thesis, University of Pittsburgh, (2010)

[14]D.J. Booth,A First Course in Statistics. Second Edition. DP Publication Ltd.,London, UK, (1992)

[15] J. Haukeand T. Kossowski, Comparison of Values of Pearson's and Spearman's Correlation Coefficient on the Same Sets of Data. Questions Geographicae, 30(2), 8793, (2011)

[16] C.Y Piaw, Mastering Research Statistics. Malaysia: McGraw Hill Education, New York, United States,(2013)

[17] J.N. Sharma, S. Tryggested, \& J. Bian, A Comprehensive Wind, Wave and Current Measurement Program in the South China Sea. Coastal Engineering 1996, 354-367, (1997)

[18] V.J. Kurian, M.S. Liew and Z. Nizamani, Statistical Modelling of Environmental Load Uncertainty for Jacket Platforms in Malaysia, IEEE Colloquium on Humanities, Science and Engineering Research (CHUSER 2012), Malaysia, (2012) 